\title{
Effects of compound Danshen injection combined with magnesium sulfate on serum MPO and hs-CRP in patients with severe preeclampsia
}

\author{
KUN YANG $^{1}$, GAOXIA DONG ${ }^{1}$, YING TIAN ${ }^{2}$ and JIAN LI $^{3}$ \\ ${ }^{1}$ Department of Obstetrics, The Second People's Hospital of Liaocheng, Liaocheng, Shandong 252600; \\ ${ }^{2}$ Department of Obstetrics, Zhangqiu Maternity and Child Care Hospital, Jinan, Shandong 250200; \\ ${ }^{3}$ Department of Obstetrics, Qingdao Central Hospital, Qingdao, Shandong 266042, P.R. China
}

Received March 7, 2018; Accepted May 11, 2018

DOI: $10.3892 /$ etm.2018.6173

\begin{abstract}
Effects of compound Danshen injection combined with magnesium sulfate on serum myeloperoxidase (MPO) and hypersensitive C-reactive protein (hs-CRP) in patients with severe preeclampsia (PE) were investigated. Five hundred patients with severe PE were randomly divided into early-onset observation, early-onset control, late-onset observation and late-onset control groups. Control group was treated with magnesium sulfate, while patients in observation group were treated with magnesium sulfate combined with compound Danshen injection. Serum levels of MPO and hs-CRP were measured by enzyme-linked immunosorbent assay (ELISA) and turbidimetric assay. The effects of compound Danshen injection combined with magnesium sulfate on the above indexes were observed. Serum levels of MPO and hs-CRP significantly decreased in early-onset observation, late-onset observation, early-onset control and late-onset control groups after treatment $(p<0.05)$. After treatment, levels of MPO and hs-CRP were significantly lower in early-onset observation group than in early-onset control group $(\mathrm{p}<0.05)$, and levels of MPO and hs-CRP were also significantly lower in late-onset observation group than in late-onset control group $(\mathrm{p}<0.05)$. Total effective rate of early-onset observation group and late-onset observation group were higher than that of early-onset control group and late-onset control group. Compound Danshen injection combined with magnesium sulfate achieved better treatment outcomes in the treatment of severe PE than magnesium sulfate alone. The combined treatment can effectively reduce the serum levels of MPO and hs-CRP.
\end{abstract}

Correspondence to: Dr Jian Li, Department of Obstetrics, Qingdao Central Hospital, 127 Siliu Nan Road, Qingdao, Shandong 266042, P.R. China

E-mail: drlijian17@163.com

Key words: MPO, severe preeclampsia, hs-CRP, compound Danshen injection, magnesium sulfate

\section{Introduction}

As a pregnancy-specific disease, preeclampsia (PE) seriously affects the health of pregnant women and the fetus. Severe PE may even bring damage to organs $(1,2)$. At present, the pathogenesis of PE is still unclear, and most scholars believe that PE is caused by systemic vascular endothelial injury after placental pathophysiological changes $(3,4)$. The pathogenesis of PE is also very complex, and may be associated with placental ischemia, genetic predisposition, immune adaptation and oxidative stress response $(5,6)$. Hypersensitive C-reactive protein (hs-CRP) is an acute inflammatory protein that is synthesized by hepatocytes. As a hemoglobinase, myeloperoxidase (MPO) is a specific marker of myeloid cells. Rosa et al $(7,8)$ found that MPO level was increased in patients with diabetes, hypertension and other metabolic diseases, suggesting that MPO is involved in the development of PE. Previous studies also showed that hs-CRP was an independent risk factor for cardiovascular disease (9). With Salvia, Panax, and borneol as major ingredients, compound Danshen injection has been widely used in the treatment of heart diseases such as angina (10). With the protective effects on blood vessel dilation, nerve and glia, magnesium sulfate can be used in the standard treatment of PE (11). In this study, serum levels of hs-CRP and MPO in 500 patients with severe PE were detected, and the effects of compound Danshen injection combined with magnesium sulfate on levels of serum MPO and hs-CRP in patients with severe PE were investigated.

\section{Patients and methods}

Selection of patients. A total of 500 patients with severe PE were selected in The Second People's Hospital of Liaocheng (Liaocheng, China) from October 2015 to May 2017. The patients included 250 with early-onset severe PE and 250 patients with late-onset severe PE. The 250 cases of early-onset PE were randomly divided into 125 cases of early-onset observation group and 125 cases of early-onset control group. Similarly, 250 cases of late-onset PE were also randomly divided into 125 cases of late-onset obser- 
Table I. Comparison of general information between groups.

\begin{tabular}{|c|c|c|c|c|c|c|}
\hline Items & $\begin{array}{c}\text { Early-onset } \\
\text { observation group }\end{array}$ & $\begin{array}{l}\text { Early-onset } \\
\text { control group }\end{array}$ & $\begin{array}{c}\text { Late-onset } \\
\text { observation group }\end{array}$ & $\begin{array}{l}\text { Late-onset } \\
\text { control group }\end{array}$ & t-value & P-value \\
\hline Cases & 125 & 125 & 125 & 125 & & \\
\hline Age (years) & $27.5 \pm 2.6$ & $26.9 \pm 3.1$ & $29.5 \pm 2.4$ & $28.7 \pm 2.7$ & 0.79 & 0.59 \\
\hline Gestational age & $31.7 \pm 1.6$ & $30.8 \pm 1.5$ & $37.2 \pm 2.1$ & $37.9 \pm 1.7$ & 11.79 & 0.002 \\
\hline Pre-pregnancy BMI (KG/M²) & $19.5 \pm 1.6$ & $18.6 \pm 2.1$ & $18.3 \pm 1.4$ & $19.3 \pm 1.8$ & 0.88 & 0.49 \\
\hline Pregnancy BMI (KG/M²) & $25.3 \pm 1.4$ & $24.7 \pm 1.2$ & $25.1 \pm 1.7$ & $24.8 \pm 1.6$ & 0.86 & 0.51 \\
\hline \multicolumn{7}{|l|}{ Blood pressure (mmHg) } \\
\hline Systolic & $160.2 \pm 5.5$ & $159.7 \pm 4.9$ & $161.2 \pm 5.7$ & $160.8 \pm 5.3$ & 0.66 & 0.67 \\
\hline Diastolic & $99.8 \pm 3.5$ & $98.2 \pm 3.2$ & $97.9 \pm 3.1$ & $99.2 \pm 2.9$ & 0.34 & 1.36 \\
\hline MAP (mmHg) & $119.2 \pm 2.3$ & $118.7 \pm 2.1$ & $119.4 \pm 2.7$ & $118.9 \pm 2.6$ & 0.59 & 0.81 \\
\hline White blood cell count $\left(\times 10^{9} / 1\right)$ & $10.3 \pm 2.4$ & $10.7 \pm 2.6$ & $8.4 \pm 2.1$ & $8.1 \pm 2.7$ & 9.56 & 0.019 \\
\hline
\end{tabular}

Table II. Comparison of serum levels of MPO and hs-CRP before and after treatment.

\begin{tabular}{|c|c|c|c|}
\hline Groups $(\mathrm{n}=125)$ & Time-points & hs-CRP (mg/l) & MPO (ng/l) \\
\hline \multirow[t]{2}{*}{$\begin{array}{l}\text { Early-onset } \\
\text { observation }\end{array}$} & $\begin{array}{l}\text { Before } \\
\text { treatment }\end{array}$ & $3.43 \pm 1.51$ & $14.79 \pm 4.24$ \\
\hline & $\begin{array}{c}\text { After } \\
\text { treatment }\end{array}$ & $1.22 \pm 0.43^{\mathrm{a} \Delta}$ & $10.75 \pm 1.31^{\mathrm{a} \Delta}$ \\
\hline \multirow[t]{2}{*}{$\begin{array}{l}\text { Late-onset } \\
\text { observation }\end{array}$} & $\begin{array}{l}\text { Before } \\
\text { treatment }\end{array}$ & $3.21 \pm 1.48$ & $14.02 \pm 3.79$ \\
\hline & $\begin{array}{c}\text { After } \\
\text { treatment }\end{array}$ & $1.04 \pm 0.52^{\mathrm{a} \Delta \Delta}$ & $10.22 \pm 1.02^{\mathrm{a} \Delta \Delta}$ \\
\hline \multirow[t]{2}{*}{$\begin{array}{l}\text { Early-onset } \\
\text { control }\end{array}$} & $\begin{array}{l}\text { Before } \\
\text { treatment }\end{array}$ & $3.64 \pm 1.69$ & $16.53 \pm 4.72$ \\
\hline & $\begin{array}{c}\text { After } \\
\text { treatment }\end{array}$ & $1.78 \pm 0.84^{\mathrm{a}}$ & $14.28 \pm 1.53^{\mathrm{a}}$ \\
\hline \multirow[t]{2}{*}{$\begin{array}{l}\text { Late-onset } \\
\text { control }\end{array}$} & $\begin{array}{l}\text { Before } \\
\text { treatment }\end{array}$ & $3.56 \pm 1.81$ & $15.38 \pm 3.98$ \\
\hline & $\begin{array}{c}\text { After } \\
\text { treatment }\end{array}$ & $1.82 \pm 0.56^{\mathrm{a}}$ & $13.37 \pm 1.45^{\mathrm{a}}$ \\
\hline
\end{tabular}

${ }^{\mathrm{a}}$ Compared with the pre-treatment level within the same group $(\mathrm{p}<0.05)$; ${ }^{\Delta}$ compared with early-onset control group $(\mathrm{p}<0.05)$; ${ }^{\Delta \Delta}$ compared with late-onset control group $(\mathrm{p}<0.05)$.

vation group and 125 cases of late-onset control group. The patients met the diagnostic criteria of PE described in 'Obstetrics and Gynecology'. Inclusion criteria: Blood pressure continually increased after the 20th week of pregnancy: Systolic blood pressure $\geq 160 \mathrm{mmHg}$ and/or diastolic blood pressure $\geq 110 \mathrm{mmHg}$; serum creatinine $\geq 1.2 \mathrm{mg} / \mathrm{dl}$; platelet $<100,000 / \mathrm{ml}\left(<100 \times 10^{9} / \mathrm{l}\right)$; proteinuria $\geq 2.0 \mathrm{~g} / 24 \mathrm{~h}$, or proteinuria using random urine samples (++). The onset gestational weeks $<34$ weeks was treated as early onset, and the onset gestational weeks $\geq 34$ weeks was treated as late onset. Exclusion criteria: Patients with diabetes, kidney, infectious and blood system diseases; patients without complete clinical data; patients with a recent medication history; patients with a history of smoking and drinking and other health damaging habits; patients gave up treatment. The patients signed informed consent, and this study was approved by the Ethics Committee of The Second People's Hospital of Liaocheng.
Treatment. Patients in early-onset and late-onset control group were subjected to intravenous injection ( $30 \mathrm{~min}$ ) of $5 \mathrm{~g}$ magnesium sulfate (SFDA approval no. 201208; Tianjin Kingyork Group Co., Ltd., Tianjin, China) in $20 \mathrm{ml} 5 \%$ glucose, then the patients were treated with intravenous injection $(30 \mathrm{~min})$ of $15 \mathrm{~g}$ magnesium sulfate in $500 \mathrm{ml} 5 \%$ glucose with a speed of $1-2 \mathrm{~g} / \mathrm{h}$, and $25-30 \mathrm{~g}$ magnesium sulfate was used every day for 10 days. Besides treatment with magnesium sulfate, patients in early-onset and late-onset observation group were also intravenously injected with compound Danshen injection (production batch no. 140514, 10-20 ml in $250 \mathrm{ml} 5 \%$ glucose; Tasly Pharmaceuticals, Inc., Tianjin, China), once per day for 10 days. Sedative and intracranial pressure drugs were also used to assist the treatment.

Detection methods and evaluation. Serum levels of hs-CRP and MPO before and 10 days after treatment were detected. Fasting venous blood samples were collected to prepare serum samples. Serum samples were stored in a fridge $\left(-4^{\circ} \mathrm{C}\right)$ before use. Serum levels of hs-CRP were measured by the turbidimetric method, using BN Prospec automatic protein analyzer (Siemens AG, Munich, Germany). Serum levels of MPO was determined by enzyme-linked immunosorbent assay (ELISA) using the kit provided by R\&D Systems, Inc. (Minneapolis, MN, USA). Efficacy evaluation criteria: Cure: Patients with proteinuria, blood pressure and other signs all returned to normal. Improved: Patients with improved proteinuria, blood pressure and other signs, and the symptoms are relieved. Invalid: No change in symptoms.

Statistical analysis. The data were processed using SPSS 22.0 statistical software (IBM Corp., Armonk, NY, USA). Data were first subjected to normal distribution test. Measurement data with normal distribution were expressed by, and t-test was used for comparison between two groups. Comparison of levels before and after treatment were performed by paired t-test. Measurement data with non-normal distribution were expressed by the median values, and comparisons between groups was performed by Wilcoxon test. ANOVA was used for comparison among multiple groups and the post hoc test was Least Significant Difference test. Ratios were compared by $\chi^{2}$ test. $\mathrm{P}<0.05$ was considered to indicate a statistically significant difference. 
Table III. Comparison of clinical efficacy (n, \%).

\begin{tabular}{lccccc}
\hline Groups & Cases & Cure & Improvement & Invalid & $\begin{array}{c}\text { Total effective } \\
\text { rate }(\%)\end{array}$ \\
\hline $\begin{array}{l}\text { Early-onset } \\
\text { observation }\end{array}$ & 125 & $54(43.2)$ & $64(51.2)$ & $7(5.60)$ & $94.4^{\mathrm{a}}$ \\
$\begin{array}{l}\text { Early-onset } \\
\text { control }\end{array}$ & 125 & $28(22.4)$ & $71(56.8)$ & $26(20.8)$ & 79.2 \\
$\begin{array}{l}\text { Late-onset } \\
\text { observation }\end{array}$ & 125 & $49(39.2)$ & $63(50.4)$ & $13(10.4)$ & $89.6^{\mathrm{b}}$ \\
$\begin{array}{l}\text { Late-onset } \\
\text { control }\end{array}$ & 125 & $24(19.2)$ & $73(58.4)$ & $28(22.4)$ & 77.6 \\
\hline
\end{tabular}

${ }^{a}$ Compared with early-onset control group $(\mathrm{p}<0.05)$; ${ }^{\mathrm{b}}$ compared with lateonset control group $(\mathrm{p}<0.05)$.

\section{Results}

Comparison of general information. Significant higher gestational age and white blood cell count were found in late-onset group than in early-onset group $(\mathrm{p}<0.05)$. No significant differences in age, pre-pregnancy BMI, pregnancy BMI and blood pressure were found between late-onset group and early-onset group ( $>>0.05)$ (Table I).

Comparison of serum levels of MPO and hs-CRP before and after treatment. After treatment, significantly lower levels of MPO and hs-CRP were found in early-onset observation group than in early-onset control group $(p<0.05)$. Similarly, significantly lower levels of MPO and hs-CRP were found in late-onset observation group than in late-onset control group $(\mathrm{p}<0.05)$ (Table II).

Comparison of clinical efficacy. Total effective rate was significantly higher in early-onset observation group and late-onset observation group than in early-onset control group and late-onset control group $(\mathrm{p}<0.05)$ (Table III).

\section{Discussion}

$\mathrm{PE}$ is a pregnancy-specific disease, and the incidence rate is $\sim 5 \%$ (12). PE can increase the risk of hypertension and other cardiovascular and cerebrovascular diseases, and the recurrence rate is high $(13,14)$. Magnesium sulfate is widely used in the treatment of PE. Magnesium sulfate can reduce intracranial pressure and bring sedation effects. Magnesium sulfate can also produce non-competitive antagonism to reduce $\mathrm{Ca}^{2+}$ concentration (15). Compound Danshen injection can improve the metabolic dysfunction caused by cell ischemia (16). Mizutani et al showed that the combination of magnesium sulfate and compound Danshen injection can effectively improve renal function and blood coagulation in patients with PE (17). In this study, effects of compound Danshen injection combined with magnesium sulfate on serum levels of MPO and hs-CRP in patients with severe PE were explored.

In this study, strict inclusion and exclusion criteria were used to select patients. So, the credibility of the results of the study was ensured. In addition, based on our knowledge, expression of MPO in severe PE has not been previously reported.

hs-CRP is a sensitive indicator of inflammation in the body's inflammatory response, and the mechanism of its function is closely related to inflammatory injury and vascular endothelial dysfunction (18). After vascular endothelial damage, the substances used to relax blood vessels will be reduced, so blood pressure will be increased (19). Ndoni et al (20) showed that hs-CRP was involved in the development of PE. Interaction between hydrogen peroxide and chloride ions can produce hypochlorite $(\mathrm{HClO})$ to form $\mathrm{MPO}-\mathrm{H}_{2} \mathrm{O}_{2}$-halogen system, and under the conditions of local defense response, MPO catalytic reaction can generate excessive oxidants to cause oxidative stress injury (21-23). In this study, serum MPO and hs-CRP levels were relatively high in patients with severe PE before treatment. After treatment with magnesium sulfate and compound Danshen injection, serum levels of MPO and HS-CRP decreased in all 4 groups. The decrease was more significant in early-onset and late-onset observation groups than in early-onset and late-onset control group, which was consistent with the study reported by Salonen et al (24), indicating that compound Danshen injection combined with magnesium sulfate can effectively reduce the level of MPO and HS-CRP in patients. Clinical effective rate and cure rate of early-onset observation group and late-onset observation group were higher than those of early-onset control group and late-onset control group. While improvement rate and invalid rate of early-onset observation group and late-onset observation group were lower than those of early-onset control group and late-onset control group, which further supported the conclusion that compound Danshen injection combined with magnesium sulfate can achieve better treatment outcomes than magnesium sulfate, which is consistent with the study reported by Alsuwaida et al (25).

This study is still limited by the small sample size, which may affect the results. More studies are needed to elucidate the pathogenesis of PE. Individualized comprehensive treatment of $\mathrm{PE}$ is needed to reduce the incidence of PE in China.

In conclusion, compound Danshen injection combined with magnesium sulfate can effectively reduce serum levels of MPO and hs-CRP, and improve patient's condition. The combined treatment can achieve better efficacy than magnesium sulfate alone.

\section{Acknowledgements}

Not applicable.

\section{Funding}

No funding was received.

\section{Availability of data and materials}

The datasets used and/or analyzed during the present study are available from the corresponding author on reasonable request.

\section{Authors' contributions}

KY wrote this manuscript and helped with treatment of patients. KY and GD analyzed and interpreted serum levels 
of hs-CRP and MPO. JL contributed significantly to statistical analysis. All authors read and approved the final manuscript.

\section{Ethics approval and consent to participate}

The study was approved by the Ethics Committee of The Second People's Hospital of Liaocheng (Liaocheng, China). Patients who participated in this research, signed the informed consent and had complete clinical data. Signed informed consents were obtained from the patients or guardians.

\section{Consent for publication}

Not applicable.

\section{Competing interests}

The authors declare that they have no competing interests.

\section{References}

1. Spaan JJ, Houben AJ, Musella A, Ekhart T, Spaanderman ME and Peeters LL: Insulin resistance relates to microvascular reactivity 23 years after preeclampsia. Microvasc Res 80: 417-421, 2010.

2. Miyakoshi K, Ishimoto H, Nishimura O, Tanigaki S, Tanaka M, Miyazaki T, Natori M and Yoshimura Y: Role of leukocytes in uterine hypoperfusion and fetal growth retardation induced by ischemia-reperfusion. Am J Physiol Heart Circ Physiol 280: H1215-H1221, 2001.

3. Cebesoy FB, Balat O, Dikensoy E, Kalayci H and Ibar Y: CA-125 and CRP are elevated in preeclampsia. Hypertens Pregnancy 28: 201-211, 2009.

4. De Silva DA, Eghdami L, McKeever M, Lee T, Tu D, Hutcheon J, Pv D, Liston R and Magee L: A causal model of magnesium sulphate use in women hospitalized at $<9$ weeks with severe or non-severe pre-eclampsia. Pregnancy Hypertens 5: 19-20, 2015.

5. Hladunewich MA, Kingdom J, Odutayo A, Burns K, Lai V, O'Brien T, Gandhi S, Zimpelmann J, Kiss A, Miller J, et al: Postpartum assessment of the renin angiotensin system in women with previous severe, early-onset preeclampsia. J Clin Endocrinol Metab 96: 3517-3524, 2011.

6. Doumatey AP, Zhou J, Adeyemo A and Rotimi C: High sensitivity $\mathrm{C}$-reactive protein (Hs-CRP) remains highly stable in long-term archived human serum. Clin Biochem 47: 315-318, 2014.

7. Rosa JS, Oliver SR, Flores RL, Ngo J, Milne GL, Zaldivar FP and Galassetti PR: Altered inflammatory, oxidative, and metabolic responses to exercise in pediatric obesity and type 1 diabetes. Pediatr Diabetes 12: 464-472, 2011.

8. Ertas IE, Kahyaoglu S, Yilmaz B, Ozel M, Sut N, Guven MA and Danisman N: Association of maternal serum high sensitive C-reactive protein level with body mass index and severity of pre-eclampsia at third trimester. J Obstet Gynaecol Res 36 : 970-977, 2010.

9. Vaerland IE, Vevatne K and Brinchmann BS: Mothers' experiences of having a premature infant due to pre-eclampsia. Scand J Caring Sci: August 10, 2017 (Epub ahead of print). doi: $10.1111 / \mathrm{scs} .12476$
10. Ren-an Q, Juan L, Chuyuan L, Wenjuan F, Chunyan H, Xuemei Y, Lin $\mathrm{H}$ and Hong N: Study of the protective mechanisms of Compound Danshen Tablet (Fufang Danshen Pian) against myocardial ischemia/reperfusion injury via the Akt-eNOS signaling pathway in rats. J Ethnopharmacol 156: 190-198, 2014.

11. Saver JL, Starkman S, Eckstein M, Stratton SJ, Pratt FD, Hamilton S, Conwit R, Liebeskind DS, Sung G, Kramer I, et al; FAST-MAG Investigators and Coordinators: Prehospital use of magnesium sulfate as neuroprotection in acute stroke. N Engl J Med 372: 528-536, 2015.

12. Carè A, Catalucci D, Felicetti $F$, Bonci D, Addario A, Gallo $P$, Bang ML, Segnalini P, Gu Y, Dalton ND, et al: MicroRNA-133 controls cardiac hypertrophy. Nat Med 13: 613-618, 2007.

13. Rahimi Z, Rahimi Z, Aghaei A and Vaisi-Raygani A: AT2R-1332 $\mathrm{G}: \mathrm{A}$ polymorphism and its interaction with AT1R $1166 \mathrm{~A}: \mathrm{C}$, ACE I/D and MMP-9 -1562 C:T polymorphisms: risk factors for susceptibility to preeclampsia. Gene 538: 176-181, 2014.

14. Ndoni E, Hoxhallari R and Bimbashi A: Evaluation of maternal complications in severe preeclampsia in a university hospital in Tirana. Open Access Maced J Med Sci 4: 102-106, 2016.

15. Prefumo $F$ and Farina A: Screening for pre-eclampsia in the first trimester: What do we still need to know before starting? Ultrasound Obstet Gynecol 50: 662-663, 2017. https://doi. org/10.1002/uog.18893.

16. Tong CX, Xing XF, Qiao SH, Liu L and Shan L: Effect of low molecular weight heparin calcium combined compound danshen injection on perinatal outcomes of nephrotic syndrome patients with early onset severe pre-eclampsia. Zhongguo Zhong Xi Yi Jie He Za Zhi 35: 957-961, 2015 (In Chinese).

17. Mizutani S and Mizutani E: New insights into the role of sex steroid hormones in pregnancy: Possible therapeutic approach by sex steroid hormones for the treatment of both preeclampsia and preterm labor. Exp Clin Endocrinol Diabetes 123: 159-164, 2015.

18. Golden MH: Nutritional and other types of oedema, albumin, complex carbohydrates and the interstitium - a response to Malcolm Coulthard's hypothesis: Oedema in kwashiorkor is caused by hypo-albuminaemia. Paediatr Int Child Health 35: 90-109, 2015

19. Rajendran P, Rengarajan T, Thangavel J, Nishigaki Y, Sakthisekaran D, Sethi G and Nishigaki I: The vascular endothelium and human diseases. Int J Biol Sci 9: 1057-1069, 2013.

20. Ndoni E, Hoxhallari R and Bimbashi A: Evaluation of maternal complications in severe preeclampsia in a university hospital in Tirana. Open Access Maced J Med Sci 4: 102-106, 2016.

21. Lees $C$ and Ferrazzi E: Relevance of haemodynamics in treating pre-eclampsia. Curr Hypertens Rep 19: 76, 2017.

22. Holmes D: Diabetes: Falling insulin requirements - a red flag for pre-eclampsia. Nat Rev Endocrinol 13: 563, 2017.

23. Liu YK, Liu ML, Wang YH, Chen H, Meng LL and Zhang JP: Role of CCL17 and CCL22 expression in dendritic cells in maternal-fetal immune tolerance. Chin J Pahophysiol 28: 10611065, 2012.

24. Salonen I, Huttunen K, Hirvonen MR, Dufva J, Groundstroem K, Dufva H, Pekkanen J and Salonen RO: Serum myeloperoxidase is independent of the risk factors of atherosclerosis. Coron Artery Dis 23: 251-258, 2012.

25. Alsuwaida A, Mousa D, Al-Harbi A, Alghonaim M, Ghareeb S and Alrukhaimi MN: Impact of early chronic kidney disease on maternal and fetal outcomes of pregnancy. J Matern Fetal Neonatal Med 24: 1432-1436, 2011.

(i) (9) This work is licensed under a Creative Commons Attribution-NonCommercial-NoDerivatives 4.0 International (CC BY-NC-ND 4.0) License. 